\title{
(2S,4E)-2-Hydroxy-4-octen-3-one, a Male-Produced Attractant Pheromone of the Cerambycid Beetle Tylonotus bimaculatus
}

\author{
Yunfan Zou ${ }^{1}$ - Jocelyn G. Millar ${ }^{1,2}$ • J. Scott Blackwood ${ }^{3}$. \\ Ryan Van Duzor ${ }^{3}$. Lawrence M. Hanks ${ }^{4}$ • Judith A. Mongold-Diers ${ }^{4}$. \\ Joseph C. H. Wong ${ }^{4}$ Ann M. Ray ${ }^{5}$
}

Received: 3 April 2015 / Revised: 17 June 2015 / Accepted: 19 June 2015 / Published online: 7 July 2015

(C) Springer Science+Business Media New York 2015

\begin{abstract}
We report the identification of a novel pheromone structure from males of the cerambycid beetle Tylonotus bimaculatus Haldeman (Cerambycinae: Hesperophanini), a species native to eastern North America. Volatiles collected from adult males contained ( $2 S, 4 E)$-2-hydroxyoct-4-en-3-one (71\%), (3R,4E)-3-hydroxyoct-4-en-2-one (15\%), (E)-4octen-2,3-dione (13\%), and 2,3-octanedione (1.5\%). Four independent field bioassays with synthetic compounds confirmed that adults of both sexes were attracted by the racemate of the major component, (E)-2-hydroxyoct-4-en-3-one. No other cerambycid species were attracted in significant numbers. Attraction of both sexes is consistent with the maleproduced pheromones of many other species in the subfamily Cerambycinae, but $T$. bimaculatus is unusual in having a pheromone chemistry that is so far unique among species in that subfamily.
\end{abstract}

Keywords Semiochemical $\cdot$ Longhorned beetle .

Aggregation pheromone $\cdot 3$-hydroxy-4-octen-2-one .

Cerambycinae

Jocelyn G. Millar

jocelyn.millar@ucr.edu

1 Department of Entomology, University of California, Riverside, CA 92521, USA

2 Department of Chemistry, University of California, Riverside, CA 92521, USA

3 USDA-APHIS-PPQ, Des Plaines, IL 60018, USA

4 Department of Entomology, University of Illinois at Urbana-Champaign, Urbana, IL 61801, USA

5 Department of Biology, Xavier University, Cincinnati, OH 45207, USA

\section{Introduction}

Research on the chemical ecology of cerambycid beetles during the last decade has revealed that many species share pheromone components having characteristic chemical structures, with even sympatric species producing pheromones of similar or even apparently identical composition (e.g., Barbour et al. 2011; Hanks and Millar 2013; Hanks et al. 2007; Mitchell et al. 2011). In particular, the $(R)$-enantiomer of 3 hydroxyhexan-2-one has been shown to be the dominant or sole component of pheromones produced by males of many species in the subfamily Cerambycinae, including sympatric species (e.g., Hanks and Millar 2013; Hanks et al. 2007; Mitchell et al. 2015). Similarly, stereoisomers of 2,3-hexanediol are common pheromone components among other species in the subfamily (e.g., Lacey et al. 2004, 2009), as well as several species in the subfamily Prioninae (Ray et al. 2012b).

To date, at least 15 compounds have been shown to be pheromone components, or likely pheromone components for nearly 30 cerambycine species native to eastern North America (e.g., Graham et al. 2012; Handley et al. 2015; Hanks and Millar 2013; Hanks et al. 2014). However, it is likely that other pheromone structures have yet to be discovered, because many cerambycine species have not been attracted by known pheromone components during screening trials conducted over almost a decade (e.g., see Hanks et al. 2014; Lingafelter 2007). Tylonotus bimaculatus Haldeman (Cerambycinae, tribe Hesperophanini) is one such species. Larvae of T. bimaculatus feed within the wood of many hardwood tree species, especially ash and privet, primarily infesting weakened or stressed trees (Solomon 1995). The adults are active during midsummer in Illinois (Hanks et al. 2014). Adults are easily sexed by the relative length of their antennae (exceeding elytral apices in males, shorter in females) and the length of the fifth abdominal sternite (shorter 
than the fourth sternite in males, longer in females; Linsley 1962). We had captured only a few adults of this species prior to 2014, despite intensive trapping efforts (see Hanks et al. 2014). This is consistent with its reported rarity (Lingafelter 2007), but the few trap catches appeared to be random with respect to trap bait, with no indication of attraction to any known cerambycid pheromone components.

Here we report the identification and synthesis of several novel compounds produced specifically by male T. bimaculatus. We further report the results of field bioassays in which the racemate of the most abundant component, (E)-2-hydroxy-4-octen-3-one, was tested as an attractant for this species.

\section{Methods and Materials}

Collection of Volatiles The first specimen of $T$. bimaculatus from which volatiles were collected was a male trapped on 19 July 2013 at a private residence in Urbana, Illinois (Champaign Co.; $40.097067^{\circ} \mathrm{N}, 88.203162^{\circ} \mathrm{W}$ ) during a bioassay that was intended for other purposes. The beetle was caught in a black corrugated plastic, cross-vane intercept trap (Alpha Scents, Portland, OR, USA) coated with Fluon ${ }^{\circledR}$ to improve capture efficiency (Graham et al. 2010). The trap had been modified to capture beetles alive by replacing trap basins with 2-1 plastic jars that had the bottoms cut out and replaced with aluminum screen. The beetle was captured in a trap baited with a blend of racemic 3-hydroxyhexan-2-one and syn- and anti-2,3-hexanediol (50 mg of each compound in $1 \mathrm{ml}$ of isopropanol) dispensed from a polyethylene sachet $\left(5.1 \times 7.6 \mathrm{~cm}\right.$, Bagettes ${ }^{\mathrm{TM}}$ model 14770, Cousin Corp., Largo, FL, USA). Another nine adults (four females, five males) were trapped alive during field bioassays in 2014 (see below) and subsequently used for collection of headspace volatiles. Captured beetles were housed individually in small screen cages under laboratory conditions ( 12:12 h L:D, $\sim 20{ }^{\circ} \mathrm{C}$ ) and fed $10 \%$ sucrose solution.

Volatiles produced by beetles were collected by aerating beetles individually in glass Mason-style canning jars (0.5 1) that were positioned near exterior windows (natural photoperiod, $\sim 14: 10 \mathrm{~h} \mathrm{~L}: \mathrm{D}, \sim 20^{\circ} \mathrm{C}$ ). Jars were swept with charcoalfiltered air ( $1 \mathrm{l} / \mathrm{min}$ ) for $24 \mathrm{~h}$, with headspace volatiles collected on a trap of adsorbent polymer (HayeSep ${ }^{\circledR}$ Q, $150 \mathrm{mg}$; Sigma-Aldrich, St. Louis, MO, USA). Aerations of jars without beetles were run simultaneously to check for system contaminants. Compounds were recovered from adsorbent traps by extraction with dichloromethane $(1.5 \mathrm{ml})$ into silanized glass vials that were stored at $-20{ }^{\circ} \mathrm{C}$ until analysis.

Analysis of Volatile Collections Aeration extracts from adult beetles were analyzed with a gas chromatograph (GC) interfaced to a mass selective detector (Models 6890 and 5973, Hewlett-Packard, Palo Alto, CA, USA) fitted with an
AT-5 ms GC column $(30 \mathrm{~m} \times 0.25 \mathrm{~mm}$ i.d., $0.25 \mu \mathrm{m}$ film; Alltech Associates, Inc., Deerfield, IL, USA). The GC oven was programmed from $35^{\circ} \mathrm{C}$ for $1 \mathrm{~min}$, then at $10^{\circ} \mathrm{C} / \mathrm{min}$ to $210^{\circ} \mathrm{C}$ and held for $3 \mathrm{~min}$. Injections were made in splitless mode with an injector temperature of $250{ }^{\circ} \mathrm{C}$ and helium carrier gas. Sex-specific peaks were identified by comparing spectra and retention times with those of authentic standards (see below).

Aeration extracts also were analyzed on a chiral stationary phase Cyclodex B GC column $(30 \mathrm{~m} \times 0.25 \mathrm{~mm}$ i.d., J\&W Scientific, Folsom CA, USA), using a temperature program of $50{ }^{\circ} \mathrm{C}$ for $1 \mathrm{~min}$, then at $3{ }^{\circ} \mathrm{C} / \mathrm{min}$ to $220^{\circ} \mathrm{C}$. Injections were made in split mode with injector temperature $100{ }^{\circ} \mathrm{C}$ to minimize thermal isomerization.

Approximately one quarter of one of the extracts was reduced by stirring with $\sim 2 \mathrm{mg}$ of $5 \% \mathrm{Pd}$ on carbon under a hydrogen atmosphere for $30 \mathrm{~min}$. The resulting mixture was filtered through a small plug of Celite ${ }^{\circledR}$ (Fisher Scientific, Fairlawn, NJ, USA) to remove the catalyst, and then analyzed by $\mathrm{GC} / \mathrm{MS}$.

Aliquots of $\sim 25 \%$ of two of the aeration extracts were reduced individually by stirring for $1 \mathrm{~h}$ with $5 \%$ rhodium on carbon under a hydrogen atmosphere. Rhodium was used rather than palladium to minimize epimerization of the chiral center. The resulting slurries were filtered through a plug of Celite and analyzed on the Cyclodex B column to determine the absolute configurations of the resulting hydrogenated products.

Sources of Chemicals The following chemicals were synthesized as described in earlier publications: syn- and anti-2,3hexanediols (Lacey et al. 2004), (R)-desmolactone (Ray et al. 2012a), prionic acid (Rodstein et al. 2009). Syn- and anti-2,3octanediols were synthesized by exactly the same method as used to make the corresponding hexanediols, substituting $(E)$ and (Z)-2-octenes (both from GFS Chemicals, Powell, OH) for $(E)$ - and $(Z)$-2-hexenes, respectively. Racemic 3hydroxydecan-2-one was synthesized by the method described by Imrei et al. (2013) for 3-hydroxyhexan-2-one, substituting 1-decyn-3-ol for 1-hexyn-3-ol as the starting material. Chemicals purchased from commercial sources included racemic 3-hydroxyhexan-2-one, racemic $(E)-6,10$ dimethylundeca-5,9-dien-2-ol [(E)-fuscumol], $(E)-6,10$ dimethylundeca-5,9-dien-2-yl acetate [ $(E)$-fuscumol acetate], and 2-(undecyloxy)ethanol (monochamol), all from Bedoukian Research, Danbury, CN, USA; acetoin (TCI America, Portland, OR, USA); racemic 2-methylbutan-1-ol and 6-methyl-5-hepten-2-one (sulcatone, Sigma-Aldrich, St. Louis, MO, USA). Analytical samples of 2,3-octanedione and the enantiomers of 2-hydroxyoctan-3-one and 3hydroxyoctan-2-one were prepared by pyridinium dichromate partial oxidation of $(2 R, 3 R)-2,3$-octanediol and (2S,3S)-2,3octanediol, which in turn were prepared as described in Wickham et al. (in preparation). 
Synthesis of Male-Produced Compounds Novel compounds identified from aeration extracts of male beetles were synthesized as described below. Unless otherwise specified, reactions were carried out in oven-dried glassware under argon. Mass spectra were obtained on an Agilent $6890 \mathrm{GC}$ fitted with a DB-17 column $(30 \mathrm{~m} \times 0.25 \mathrm{~mm}$ i.d.; J\&W Scientific, Folsom CA, USA), interfaced to an Agilent 5973 mass selective detector, run in electron impact ionization mode at $70 \mathrm{eV}$. ${ }^{1} \mathrm{H}$ NMR spectra were recorded as $\mathrm{CDCl}_{3}$ solutions on a Varian INOVA-400 spectrometer at $400 \mathrm{MHz}$ for protons.

(E)-2-Hydroxy-4-octen-3-one (5) (Fig. 1) 1-(Benzotriazol-1yl)-1-ethoxy-(E)-2-hexene (2) was prepared from $(E)-2$ hexenal diethyl acetal 1 (TCI America, Portland, OR, USA), and benzotriazole as previously described (Katritzky et al. 1997a). $n$-BuLi (2.3 M in hexane, $3.0 \mathrm{ml}, 6.9 \mathrm{mmol}$ ) was added to a solution of $2(1.67 \mathrm{~g}, 6.81 \mathrm{mmol})$ in THF $(45 \mathrm{ml})$ at $-78^{\circ} \mathrm{C}$ under $\mathrm{Ar}$, and after stirring at this temperature for $5 \mathrm{~min}$, acetaldehyde (5 M in THF, $1.5 \mathrm{ml}, 7.5 \mathrm{mmol}$ ) was added. The solution was stirred at $-78^{\circ} \mathrm{C}$ for $10 \mathrm{~min}$, then quenched at this temperature with water $(45 \mathrm{ml})$. Aqueous $\mathrm{HCl}(2 \mathrm{M}, 7 \mathrm{ml})$ was then added, and the mixture was stirred at room temperature for $4 \mathrm{~h}$. The resulting solution was extracted twice with $\mathrm{Et}_{2} \mathrm{O}$, and the combined ether extracts were washed twice with saturated $\mathrm{Na}_{2} \mathrm{CO}_{3}$ solution, once with brine, and dried over anhydrous $\mathrm{Na}_{2} \mathrm{SO}_{4}$. After concentration, the crude product was purified by flash chromatography on silica gel (hexanes/EtOAc $=5 / 1, \mathrm{R}_{\mathrm{f}}=$ $0.30)$ to give racemic $(E)$-2-hydroxy-4-octen-3-one $\mathbf{5}$ as a yellow oil $(0.58 \mathrm{~g}, 60 \%) .{ }^{1} \mathrm{H}$ NMR $\delta 7.02(\mathrm{dt}, J=15.6,7.0 \mathrm{~Hz}$, $1 \mathrm{H}), 6.20$ (dt, $J=16.0,1.6 \mathrm{~Hz}, 1 \mathrm{H}), 4.42(\mathrm{dq}, J=7.0,5.6 \mathrm{~Hz}$, $1 \mathrm{H}), 3.63(\mathrm{~d}, J=5.2 \mathrm{~Hz}, 1 \mathrm{H}), \mathrm{m}(2.25-2.19,2 \mathrm{H}), \mathrm{m}(1.55-1.46$, $2 \mathrm{H}), 1.35$ (d, $J=6.8 \mathrm{~Hz}, 3 \mathrm{H}), 0.93$ (t, $J=7.2 \mathrm{~Hz}, 3 \mathrm{H})$. The ${ }^{1} \mathrm{H}$ NMR spectrum was in agreement with that previously reported (Cosp et al. 2008). The enantiomers were separated by $0.8 \mathrm{~min}$ on the Cyclodex B GC column.

To prepare larger quantities of $\mathbf{5}$ for field bioassays, crude $\mathbf{5}$ was purified by Kugelrohr distillation instead of flash chromatography. After a forerun was taken at $40{ }^{\circ} \mathrm{C} / 0.3$ torr, $(E)$ 2-hydroxy-4-octen-3-one 5 was collected at $\sim 78{ }^{\circ} \mathrm{C} / 0.6$ torr ( $\sim 87 \%$ pure by GC).

Fig. 1 Syntheses of $(E)$-2hydroxy-4-octen-3-one and $(E)$ 4-octen-2,3-dione $(\mathrm{Bt}=1$ benzotriazolyl)
(E)-4-Octen-2,3-dione (7) (Fig. 1) $n$-BuLi (2.3 M in hexane, $2.2 \mathrm{ml}, 5.1 \mathrm{mmol})$ was added to a solution of triazole $2(1.23 \mathrm{~g}$, $5.0 \mathrm{mmol})$ in THF $(50 \mathrm{ml})$ at $-78{ }^{\circ} \mathrm{C}$ under Ar. The solution was stirred at this temperature for $5 \mathrm{~min}$ and then $n$-butyl acetate $(0.72 \mathrm{ml}, 5.5 \mathrm{mmol})$ was added. The solution was stirred at $-78^{\circ} \mathrm{C}$ for $10 \mathrm{~min}$, then quenched at this temperature with water $(50 \mathrm{ml})$. Aqueous $\mathrm{HCl}(2 \mathrm{M}, 6 \mathrm{ml})$ was added, and the mixture was stirred at room temperature for $4 \mathrm{~h}$. The resulting solution was extracted twice with $\mathrm{Et}_{2} \mathrm{O}$, and the combined ether extracts were washed twice with $0.5 \mathrm{M} \mathrm{NaOH}$ and once with brine, then dried over anhydrous $\mathrm{Na}_{2} \mathrm{SO}_{4}$, and concentrated. The residue was purified by flash chromatography (hexanes/EtOAc $=95 / 5)$ to give 7 as a yellow oil $(0.10 \mathrm{~g}$, $14 \%$ ). Because only a small amount was required as an analytical standard, no attempts were made to improve the yield. ${ }^{1} \mathrm{H}$ NMR $\delta 7.17$ (dt, $\left.J=16.0,6.8 \mathrm{~Hz}, 1 \mathrm{H}\right), 6.73(\mathrm{dt}, J=16.0$, $1.6 \mathrm{~Hz}, 1 \mathrm{H}), 2.38$ (s, 3H), 2.27 (qd, $J=7.2,1.6 \mathrm{~Hz}, 2 \mathrm{H}), 1.53$ (m, 2H), 0.95 (t, $J=7.2 \mathrm{~Hz}, 3 \mathrm{H})$. The ${ }^{1} \mathrm{H}$ NMR spectrum was in accord with that previously reported (Katritzky et al. 1997b).

(E)-3-Hydroxy-4-octen-2-one (10) (Fig. 2) (E)-1-(2-methyl1,3-dithian-2-yl)hex-2-en-1-ol (9) was prepared by adding $n$ $\operatorname{BuLi}(2.3 \mathrm{M}$ in hexane, $2.2 \mathrm{ml}, 5.1 \mathrm{mmol})$ dropwise to a solution of 2-methyl-1,3-dithiane $8(0.67 \mathrm{~g}, 5.0 \mathrm{mmol})$ in THF $(40 \mathrm{ml})$ at $-20{ }^{\circ} \mathrm{C}$ under $\mathrm{Ar}$, and the resulting solution was stirred at $-20^{\circ} \mathrm{C}$ for $1 \mathrm{~h}$. The solution was then cooled to $-78{ }^{\circ} \mathrm{C}$ and $(E)$-2-hexenal $(0.58 \mathrm{ml}, 5.0 \mathrm{mmol})$ was added dropwise. The reaction was stirred for $30 \mathrm{~min}$, then quenched with saturated aq. $\mathrm{NH}_{4} \mathrm{Cl}$ solution, and extracted with $\mathrm{Et}_{2} \mathrm{O}$. The ether extract was washed with brine, dried over anhydrous $\mathrm{Na}_{2} \mathrm{SO}_{4}$, concentrated, and the crude product was purified by flash chromatography (hexanes/EtOAc $=9 / 1$ ). The resulting product contained a small amount of 6-decen-5-ol, the addition product of $n$-BuLi to $(E)-2$-hexenal, which cochromatographed with 9 . This impurity was easily removed by Kugelrohr distillation at $\sim 75{ }^{\circ} \mathrm{C} / 0.1$ torr, leaving 9 as the residue, as a colorless oil $(0.88 \mathrm{~g}, 75 \%) .{ }^{1} \mathrm{H}$ NMR $\delta 5.85$ (dtd, $J=15.6,6.8,1.2 \mathrm{~Hz}, 1 \mathrm{H}), 5.63$ (dd, $J=15.6,6.0 \mathrm{~Hz}, 1 \mathrm{H}), 4.46$ (d, $J=6.0 \mathrm{~Hz}, 1 \mathrm{H}), 3.02(\mathrm{~m}, 2 \mathrm{H}), 2.74(\mathrm{~d}, J=1.6 \mathrm{~Hz}, 1 \mathrm{H}), 2.65$

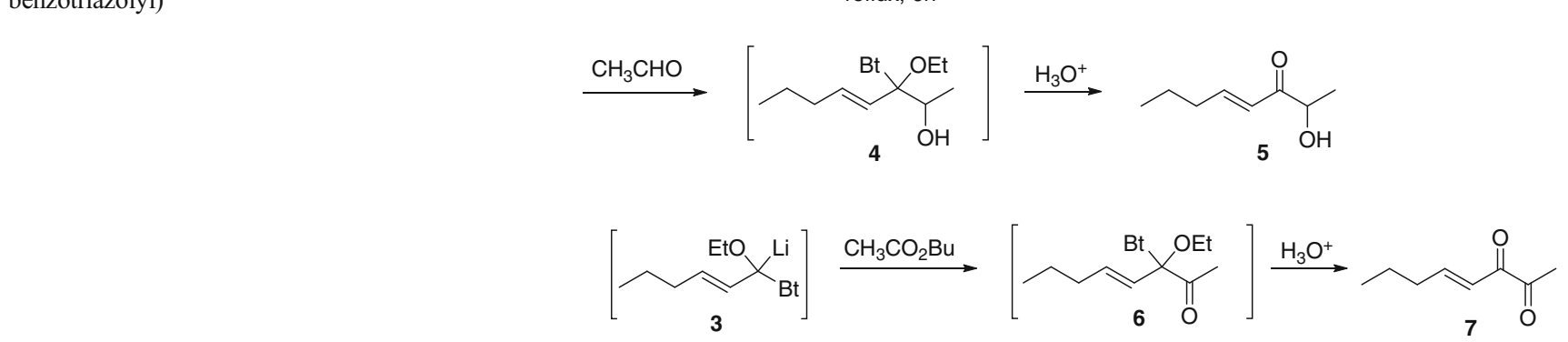


Fig. 2 Synthesis of $(E)-3-$ hydroxy-4-octen-2-one
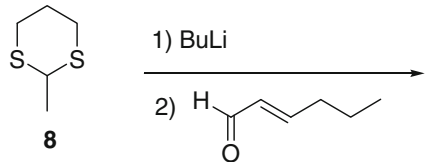

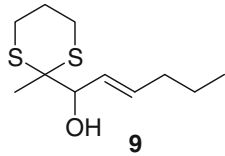

$\underset{\mathrm{CH}_{3} \mathrm{CN}, \mathrm{H}_{2} \mathrm{O}}{\stackrel{\mathrm{AgNO}_{3}, \mathrm{NCS}}{\longrightarrow}}$

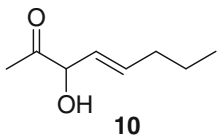

(m, 2H), 2.12-2.05 (m, 3H), 1.93-1.83 (m, 1H), $1.43(\mathrm{~m}, 2 \mathrm{H})$, 1.39 (s, 3H), 0.91 (t, $J=7.4 \mathrm{~Hz}, 3 \mathrm{H})$. The ${ }^{1} \mathrm{H}$ NMR spectrum agreed with that previously reported (Sikorski and Reich 2001).

Alcohol 9 (0.23 g, $1.0 \mathrm{mmol})$ was dissolved in $\mathrm{CH}_{3} \mathrm{CN}$ $(1.5 \mathrm{ml})$ and added in one portion to a well-stirred solution of $N$-chlorosuccinimide $(0.40 \mathrm{~g}, 3.0 \mathrm{mmol})$ and $\mathrm{AgNO}_{3}$ $(0.59 \mathrm{~g}, 3.5 \mathrm{mmol})$ in $15 \mathrm{ml} \mathrm{9:1}$ acetonitrile:water cooled to $0{ }^{\circ} \mathrm{C}$. The solution was stirred for $30 \mathrm{~min}$ and then treated with saturated aqueous $\mathrm{Na}_{2} \mathrm{~S}_{2} \mathrm{O}_{3}$. The reaction mixture was extracted with $\mathrm{Et}_{2} \mathrm{O}$, and the ether extract was washed with saturated $\mathrm{Na}_{2} \mathrm{CO}_{3}$, water, and brine. The organic layer was dried over anhydrous $\mathrm{Na}_{2} \mathrm{SO}_{4}$ and concentrated, and the crude product was purified by flash chromatography (hexanes/EtOAc $=9 / 1$ ) to give $\mathbf{1 0}$ as a colorless oil $(22 \mathrm{mg}, 16 \%)$. No attempts were made to optimize the yield. The purified compound was quite unstable, partially decomposing at room temperature overnight. ${ }^{1} \mathrm{H}$ NMR $\delta 5.95(\mathrm{~m}, 1 \mathrm{H}), 5.38$ (qt, $J=8.0,1.6 \mathrm{~Hz}$, $1 \mathrm{H}), 4.55$ (dd, $J=8.0,4.8 \mathrm{~Hz}, 1 \mathrm{H}), 3.70$ (d, $J=4.8 \mathrm{~Hz}, 1 \mathrm{H})$, $2.21(\mathrm{~s}, 3 \mathrm{H}), 2.11-2.04(\mathrm{~m}, 2 \mathrm{H}), 1.47-1.41(\mathrm{~m}, 2 \mathrm{H}), 0.92(\mathrm{t}$, $J=7.2 \mathrm{~Hz}, 3 \mathrm{H}$ ). The ${ }^{1} \mathrm{H}$ NMR spectrum was in agreement with that previously reported (Cosp et al. 2008).

Field Bioassays of Synthetic (E)-2-Hydroxy-4-octen-3-one Attraction of adult $T$. bimaculatus to the dominant component in aerations of males, $(E)$-2-hydroxy-4-octen-3-one, was confirmed in four independent field bioassays that used the same types of traps and lures as described above. Traps used in Bioassays 1 and 2 were modified for trapping beetles alive for aeration as described above, whereas those used in Bioassays 3 and 4 had the trap basins partly filled with propylene glycol to kill and preserve beetles. As expected, beetles of several cerambycid species were captured by traps baited with known attractants, notably the very common species Neoclytus acuminatus acuminatus (F.), Neoclytus mucronatus mucronatus (F.), and Xylotrechus colonus (F.) (e.g., Hanks and Millar 2013). Those data will be presented elsewhere.

In Bioassay 1, two traps were set at least $10 \mathrm{~m}$ apart, one baited with (E)-2-hydroxy-4-octen-3-one $(50 \mathrm{mg}$ in $1 \mathrm{ml}$ isopropanol), and the other with a lure containing $1 \mathrm{ml}$ of isopropanol (control). One pair of traps was deployed at the private residence mentioned above during 18 June -15 July 2014, and three pairs of traps (pairs at least $100 \mathrm{~m}$ apart) were deployed at Forest Glen Preserve (Vermilion Co., IL, USA; $40.01516 \mathrm{~N}, 87.56771 \mathrm{~W}$ ) during 11 July -6 August 2014. Traps were checked for beetles every $1-3$ days $(N=10$, and 8 samples for the two sites, respectively), at which time treatments were switched within trap pairs to control for location effects.
Bioassay 2 was conducted at both Forest Glen Preserve and Allerton Park (Piatt Co., IL; 39.985342 N, 88.650147 W), and was intended to assess attraction of multiple cerambycid species (including T. bimaculatus) to a variety of chemicals and blends that were known or suspected attractant pheromones. The seven experimental treatments included: (1) (E)-2-hydroxy-4-octen3-one; (2) acetoin; (3) acetoin + 3-hydroxyhexan-2-one; (4) sulcatone; (5) $(R)$-desmolactone, pheromone of the lepturine Desmocerus c. californicus Horn (Ray et al. 2012a); (6) racemic prionic acid, pheromone of several Prionus species (Barbour et al. 2011); and (7) a generic lure consisting of a blend of 3-hydroxyhexan-2-one, syn-2,3-hexanediol, $(E)$ fuscumol, $(E)$-fuscumol acetate, monochamol, and racemic 2methylbutan-1-ol (see Hanks and Millar 2013). The bioassay was deployed from 9 June to 6 August 2014, and traps were checked for captured beetles at intervals of 2-3 days $(N=25$ samples), at which time treatments were switched within trap lines to control for location effects.

Bioassays 3 and 4 were conducted in the vicinity of Chicago, IL (Cook Co.) during 27 June - 30 July 2014, and targeted the exotic cerambycid Trichoferus campestris (Faldermann), that has recently become established in the midwestern and western United States (Bullas-Appleton et al. 2014). The four treatments for Bioassay 3 included the candidate pheromone of T. bimaculatus, because that species is in the same tribe as T. campestris (Hesperophanini), along with three blends of synthetic compounds that were considered potential attractants of the exotic species based on previous research with cerambycines (e.g., Hanks and Millar 2013; Mitchell et al. 2015; Narai et al. 2015; Schroeder 1996). Thus, treatments were as follows: (1) (E)-2-hydroxy-4-octen-3-one; (2) Blend 1 (3-hydroxyhexan-2-one + 3-hydroxyoctan-2-one +3 -hydroxydecan-2-one + sulcatone +2 -methylbutan-1-ol; (3) Blend 2 (syn-2,3-hexanediol + syn-2,3-octanediol +2 methylbutan-1-ol); and (4) Blend 3 (anti-2,3-hexanediol + anti-2,3-octanediol + 2-methylbutan-1-ol). Each trap also had a lure that released ethanol, consisting of a polyethylene sachet $\left(10 \times 15 \mathrm{~cm}\right.$, Bagettes ${ }^{\mathrm{TM}}$ model 14772, Cousin Corp., Largo, FL, USA) containing $100 \mathrm{ml}$ of $95 \% \mathrm{EtOH}$, which was hung from the top of the trap. Sets of four traps (at least $10 \mathrm{~m}$ apart) were set up at three sites in the Chicago area: Mallard Lake (DuPage Co. Forest Preserve; 41.96130 N, 88.12591 W), Busse Woods (Cook Co. Forest Preserve; 42.03343 N, 87.98658 W), and Robinson Woods South (Cook Co. Forest Preserve; 41.96146 N, 87.85796 W). Traps were checked for captured beetles at intervals of 6 9 days ( $N=4$ samples), at which time treatments were switched within trap lines to control for location effects. 
In Bioassay 4, pairs of traps were baited with combinations of the same treatments used in Bioassay 3, including: (1) $(E)$ 2-hydroxy-4-octen-3-one + Blend 2, and (2) Blend $1+$ Blend 3. Traps were set $(\sim 100 \mathrm{~m}$ apart) at three sites: (1) an area of warehouses near the village of Carol Stream (DuPage Co.; $41.90929 \mathrm{~N}, 88.11574 \mathrm{~W}$ ); (2) a Metra train station near the Schaumburg airport (Cook Co.; 41.98904 N, 88.12006 W); and (3) a rail yard in Cook Co. (41.96458 N, $87.86698 \mathrm{~W})$. Traps were checked for captured beetles at intervals of $6-$ 9 days $(N=4$ samples), and at each count treatments were switched within trap pairs to control for location effects.

For each bioassay, the treatment mean catch of T. bimaculatus by (E)-2-hydroxy-4-octen-3-one, or the blend that included it, was compared with the mean catch for other treatments which were considered as controls. Overall differences between treatment means, blocked by site and date, were tested using the nonparametric Friedman's Test (PROC FREQ, option CMH; SAS Institute 2008). Differences between pairs of means were tested with the nonparametric Nemenyi multiple comparison test (Elliot and Hynan 2011; Zar 2010). Replicates that contained no T. bimaculatus at all were not included in analyses. Daily flight period was estimated from data for a few beetles captured on days when traps had been checked repeatedly.

\section{Results}

Identification of Sex-Specific Compounds Analyses of collections of volatiles from male T. bimaculatus beetles typically contained either no discernable insect-produced compounds, or multimicrogram amounts from overnight aerations of individual male beetles. Analyses showed four peaks $(1.5,13,15$, and $71 \%$, respectively) that were reproducibly present in the five aeration extracts that contained detectable quantities of insect-produced compounds. These compounds were not detected in any of the aeration extracts obtained from females, or from control aerations.

In order of elution on the AT-5ms GC column, the first peak was tentatively identified as 2,3-octanedione from its small molecular ion at $m / z 142(4 \%)$, a base peak at $m / z 43$, a significant fragment at $\mathrm{m} / \mathrm{z} 99$ (43\%) from cleavage of the $\mathrm{C}-\mathrm{C}$ bond between the two carbonyl groups, and $\mathrm{m} / \mathrm{z} 71$ (38\%) from cleavage $\alpha$ to the diketone.

The second peak appeared to be the unsaturated analog $\Delta 4$-octen-2,3-dione, with a small molecular ion at $\mathrm{m} / \mathrm{z} 140$ $(1 \%)$, significant fragments at $\mathrm{m} / \mathrm{z} 97(72 \%)$ and $43(23 \%)$ from cleavage between the two carbonyls, and a base peak at $m / z 55\left(\mathrm{C}_{4} \mathrm{H}_{7}^{+}\right.$or $\left.\mathrm{C}_{3} \mathrm{H}_{3} \mathrm{O}^{+}\right)$that was not readily assignable.

In combination with these data, the identifications of the third and fourth peaks were suggested by the presence of two small peaks that eluted shortly before the third major peak. These were identified as 2-hydroxyoctan-3-one and 3- hydroxyoctan-2-one by comparison with authentic standards. The third peak had a small molecular ion at $m / z 142(<1 \%)$, and significant ions at $\mathrm{m} / \mathrm{z} 99(45 \%)$ and 43 (28\%) from possible cleavages between carbons 2 and 3 of a 3-hydroxy4-octen-2-one structure. The assignment of the base peak at $m / z 57\left(\mathrm{C}_{4} \mathrm{H}_{9}^{+}\right.$or $\left.\mathrm{C}_{3} \mathrm{H}_{5} \mathrm{O}^{+}\right)$was not immediately apparent.

Finally, the mass spectrum of the latest eluting peak was suggestive of the regioisomer, 2-hydroxy-4-octen-3-one, with a small molecular ion at $\mathrm{m} / \mathrm{z} 142(<1 \%)$, the base peak at $\mathrm{m} / \mathrm{z}$ 97 (100\%), a significant $\mathrm{m} / \mathrm{z} 45$ (26\%) from cleavage between the alcohol and ketone groups, and a large fragment $(98 \%)$ at $m / z 55$.

Further evidence in support of these identifications was supplied by catalytic hydrogenation of an aliquot of an aeration extract over palladium. The resulting GC/MS chromatogram showed only three peaks, which were readily identified as 2 , 3-octanedione, 2-hydroxyoctan-3-one, and 3-hydroxyoctan-2one. The identities of the four compounds were confirmed to be 2,3-octanedione, $(E)$-4-octen-2,3-dione, $(E)$-3-hydroxy-4octen-2-one, and (E)-2-hydroxy-4-octen-3-one by synthesis of the appropriate standards, and matching their retention times and mass spectra with those of the compounds in the extracts.

Racemic (E)-2-hydroxyoct-4-en-3-one gave two wellseparated peaks (24.06 and $24.85 \mathrm{~min}$, respectively) when analyzed on a chiral stationary phase Cyclodex B column. The retention time of the insect-produced compound matched that of the later eluting peak. Authentic standards of the enantiomers of (E)-2-hydroxyoct-4-en-3-one were not available, and so the absolute configurations of both this compound and the insect-produced (E)-3-hydroxyoct-4-en-2-one were determined indirectly from the hydrogenated aeration samples. On the Cyclodex B column, $(S)$-2-hydroxyoctan-3-one and $(R)$-3-hydroxyoctan-2-one partially overlapped (22.80 and $22.72 \mathrm{~min}$, respectively), whereas $(R)$-2-hydroxyoctan3 -one $(22.56 \mathrm{~min})$ and $(S)$-3-hydroxyoctan-2-one $(23.38 \mathrm{~min})$ were well separated from each other and from the overlapping peaks. Analysis of the aliquots of two aeration extracts hydrogenated over rhodium showed a large broadened peak at $22.68 \mathrm{~min}$ with an obvious shoulder, and a small peak at the retention time of $(R)$-2-hydroxyoctan-3-one. These results indicated that the compounds in the hydrogenated extract consisted primarily of (S)-2-hydroxyoctan-3-one, and $(R)$-3-hydroxyoctan-2-one. The small amount of $(R)-2$ hydroxyoctan-3-one was probably the result of isomerization during handling or analysis, because analysis of the crude aeration extracts on the Cyclodex B column before hydrogenation showed essentially a single $(E)$-2-hydroxy-4-oct-4-en3 -one peak. Coinjection of the hydrogenated aeration extracts with authentic standards confirmed the identifications. These results also allowed us to assign the retention time order of the two enantiomers of (E)-2-hydroxy-4-octen-3-one on the Cyclodex B column, with the later eluting enantiomer having the $(S)$-configuration. 
Synthesis of Male-Produced Compounds Racemic $(E)-2-$ hydroxy-4-octen-3-one $\mathbf{5}$ was readily synthesized from commercially available (E)-2-hexenal diethyl acetal 1 (Fig. 1). Thus, refluxing 1 with benzotriazole resulted in replacement of one of the two ethoxy groups, to give 2 (Katritzky et al. 1997a). Treatment of $\mathbf{2}$ with one equivalent of butyllithium at $-78{ }^{\circ} \mathrm{C}$ gave benzotriazole-stabilized allylic anion $\mathbf{3}$, which upon reaction with acetaldehyde yielded intermediate 4 , which was directly hydrolyzed with dilute aqueous acid to the desired (E)-2-hydroxy-4-octen-3-one 5. The reaction proceeded regioselectively, with no byproducts from attack at the $\gamma$-position being observed. Furthermore, the sequence was scalable, allowing for production of multigram quantities of material for field trials, although Kugelrohr distillation for purification of the final product, rather than flash chromatography, gave material of $87 \%$ purity compared to the essentially pure material ( $>99 \%$ by GC) obtained by chromatographic purification.

Similarly, treatment of anion 3 with $n$-butyl acetate, followed by hydrolysis of the resulting intermediate 6 gave $(E)-4-$ octen-2,3-dione 7 (Fig. 1). (E)-3-Hydroxy-4-octen-2-one 10, the regioisomer of $\mathbf{5}$, was prepared in two steps by regioselective 1,2-addition of the anion from dithiane 8 to $(E)$-2-hexenal to give allylic alcohol 9 (Sikorski and Reich 2001; Chen and Micalizio 2012), followed by removal of the dithiane protecting group to give (E)-3-hydroxy-4-octen-2-one $\mathbf{1 0}$ (Bow et al. 2010; Fig. 2).

Field Bioassays of Synthetic Racemic (E)-2-Hydroxy-4octen-3-one Only a few adult T. bimaculatus were captured during Bioassay 1, with five beetles at the private residence (on four dates) and four beetles at the Forest Glen Preserve site (three dates). Nevertheless, every beetle was in a trap baited with $(E)$-2-hydroxy-4-octen-3-one, and the mean $( \pm 1 \mathrm{SE})$ for the pheromone treatment $(1.3 \pm 0.18)$ was significantly different from the 0 mean for controls (Friedman's $Q_{1,14}=7.0, P=$ 0.008 ). Five of the 9 beetles caught were females. Traps baited with (E)-2-hydroxy-4-octen-3-one, and control traps, captured only a few specimens of other cerambycid species, with no evidence of significant attraction to either.

During Bioassay 2, 12 adult $T$. bimaculatus were caught on eight of 25 sample dates, and again all were in traps baited with $(E)$-2-hydroxy-4-octen-3-one. The mean for the pheromone treatment $(1.5 \pm 0.3)$ was significantly different than the 0 means for the remaining treatments $\left(Q_{7,64}=16.7, P<0.001\right.$; Nemenyi test, $P<0.05$ ). The sex ratio was $\sim 58 \%$ females. Traps baited with $(E)$-2-hydroxy-4-octen-3-one captured only one beetle each of two other cerambycid species, while those baited with the multispecies generic lures captured 90 beetles of 16 cerambycid species (data not presented).

During Bioassay 3 in the Chicago area, 45 adult T. bimaculatus were captured, of which 43 ( $\sim 96 \%)$ were in traps baited with (E)-2-hydroxy-4-octen-3-one (Fig. 3; means

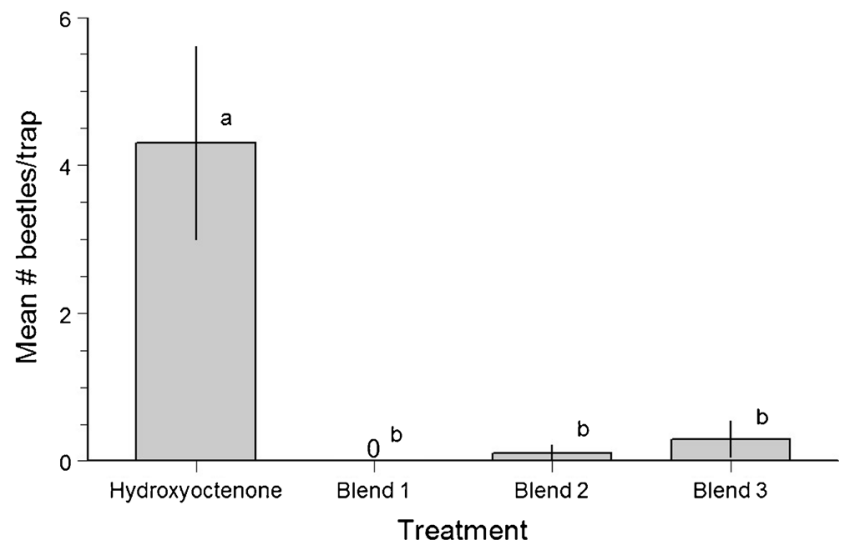

Fig. 3 Mean $( \pm 1$ SE) number of Tylonotus bimaculatus (sexes combined) captured by traps baited with synthetic pheromones in Cook Co., Illinois. Compound abbreviations: "Hydroxyoctenone": $(E)-2-$ hydroxy-4-octen-3-one; "Blend 1": 3-hydroxyhexan-2-one + 3hydroxyoctan-2-one +3 -hydroxydecan-2-one + sulcatone +2 methylbutan-1-ol; "Blend 2": syn-2,3-hexanediol + syn-2,3-octanediol + 2-methylbutan-1-ol; "Blend 3": anti-2,3-hexanediol + anti-2,3-octanediol + 2-methylbutan-1-ol. Means with different letters are significantly different (Nemenyi test, $P<0.05$ )

significantly different, $\left.Q_{3,36}=15.7, P<0.001\right)$. The sex ratio was $\sim 44 \%$ females. Traps baited with $(E)$-2-hydroxy-4octen-3-one caught no other species in significant numbers, including the original target species of this particular field bioassay, T. campestris (no specimens).

Another seven adult $T$. bimaculatus were captured during Bioassay 4, and all were in traps baited with the blend of chemicals that included (E)-2-hydroxy-4-octen-3-one. The mean catch of $T$. bimaculatus in traps baited with that blend was $1.2 \pm 0.17$, whereas no $T$. bimaculatus were captured in traps baited with the other blend (means significantly different; $Q_{2,12}=6.8, P<0.006$ ). Six of the seven beetles were females. Again, traps baited with the blend containing $(E)-2-$ hydroxy-4-octen-3-one attracted only a few beetles of other cerambycid species, with no apparent trends with regard to treatment.

Considering all 75 adult $T$. bimaculatus that were captured during the field bioassays, the average ( $\pm 1 \mathrm{SD}$ ) ordinal date of capture was $192 \pm 10.8$, corresponding to $\sim 6-16$ July. Beetles were active between 9:00 and 10:00 PM $(N=3$ observation dates). The overall sex ratio of beetles captured by traps baited with $(E)$-2-hydroxy-4-octen-3-one was $52 \%$ female.

\section{Discussion}

Field bioassays confirmed that adult $T$. bimaculatus of both sexes were specifically attracted to racemic $(E)$-2-hydroxy-4octen-3-one, and not to any of the other compounds tested. Furthermore, there were no indications that this compound was attractive to any of the other cerambycid species endemic to the Midwestern regions where traps were deployed. This 
apparent species specificity is in marked contrast to the 2hydroxyalkan-3-one and 3-hydroxyalkan-2-one analogs, which usually attract multiple species in field bioassays (e.g., Hanks and Millar 2013; Hanks et al. 2014; Wickham et al. 2014). Although (E)-2-hydroxy-4-octen-3-one is a novel pheromone component, it is an unsaturated analog of the vicinal hydroxyalkanones found in many cerambycid pheromones, rather than representing an entirely new pheromone motif.

The bioassay results showed that the racemic form of the dominant compound produced by male T. maculatus, $(E)-2$ hydroxyoct-4-en-3-one, is sufficient to attract conspecifics. Analyses of aeration extracts indicated that males produced primarily or exclusively the $(S)$-enantiomer of this compound, but, to date, we have not synthesized and tested the pure enantiomer $v s$. the racemate to ascertain whether the unnatural $(R)$-enantiomer is benign, or whether it may decrease or enhance attraction to the $(S)$-enantiomer.

It is not known what role, if any, is played by the remaining three components. Field trials were not attempted with $(E)-3-$ hydroxyoct-4-en-3-one because the synthesized compound proved to be quite unstable, partially decomposing overnight at room temperature. In addition, the small amounts of the two diketones detected in the extracts may be analytical artifacts. For example, in previous studies we have noted that 2,3alkanediones are frequently present in aeration samples that contain 3-hydroxyalkan-2-ones (Millar et al. 2009). Although both $(E)$-2-hydroxy-4-octen-3-one and (E)-3-hydroxy-4octen-2-one have been reported as synthetic products from enzyme-catalyzed reactions of $\alpha, \beta$-unsaturated aldehydes with aldehydes (Cosp et al. 2008), to our knowledge, neither has been identified from natural sources before.

Attraction of both sexes of T. bimaculatus by (E)-2-hydroxy-4-octen-3-one is consistent with the aggregation-sex pheromones (sensu Cardé 2014) produced by males of many species in the same subfamily (Cerambycinae), as well as cerambycids in the subfamilies Lamiinae and Spondylidinae (e.g., Hanks and Millar 2013; Mitchell et al. 2011; Sweeney et al. 2010). To our knowledge, no pheromones have been identified for any other species in the same tribe as T. bimaculatus (Hesperophanini), although both sexes of a species in this tribe, Brothylus gemmulatus LeConte, were attracted to traps baited with $(R)$-3-hydroxyhexan-2-one in previous field screening trials (Hanks et al. 2007).

In summary, the results reported here extend the types of structural variations seen in 6-, 8-, and 10-carbon compounds with oxygens in the 2 and 3 positions that make up the bulk of the known pheromone components produced by male cerambycids in the subfamily Cerambycinae. However, in contrast to most of the other pheromone compounds in this general class, $(E)$-2-hydroxy-4-octen-3-one may be relatively species-specific because we saw no indication of attraction of any other species to this compound during four different bioassays.
Acknowledgments We thank Steve Buck and the University of Illinois Committee on Natural Areas, the Vermilion County Conservation District, and the Forest Preserve Districts of Cook and DuPage Counties for access to field sites. We gratefully acknowledge financial support from The Alphawood Foundation of Chicago and USDA APHIS PPQ (agreement 14-8130-0362-CA).

\section{References}

Barbour JD, Millar JG, Rodstein J, Ray AM, Alston DG, Rejzek M, Dutcher JD, Hanks LM (2011) Synthetic 3,5-dimethyldodecanoic acid serves as a general attractant for multiple species of Prionus (Coleoptera: Cerambycidae). Ann Entomol Soc Am 104:588-593

Bow WF, Basak AK, Jolit A, Vicic DA, Tius MA (2010) Enamineiminium ion Nazarov cyclization of $\alpha$-ketoenones. Org Lett 12 : $440-443$

Bullas-Appleton E, Kimoto T, Turgeon JJ (2014) Discovery of Trichoferus campestris (Coleoptera: Cerambycidae) in Ontario, Canada and first host record in North America. Can Entomol 146: $111-116$

Cardé RT (2014) Defining attraction and aggregation pheromones: teleological versus functional perspectives. J Chem Ecol 40:519-520

Chen MZ, Micalizio GC (2012) Three-component coupling sequences for the regiospecific synthesis of substituted pyridines. J Am Chem Soc 134:1352-1356

Cosp A, Dresen C, Pohl M, Walter L, Röhr C, Müller M (2008) $\alpha$, $\beta$ Unsaturated aldehydes as substrates for asymmetric $\mathrm{C}-\mathrm{C}$ bond forming reactions with thiamin diphosphate (ThDP)-dependent enzymes. Adv Synth Catal 350:759-771

Elliot AC, Hynan LS (2011) A SAS ${ }^{\circledR}$ macro implementation of a multiple comparison post hoc test for a Kruskal-Wallis analysis. Comput Methods Prog Biomed 102:75-80

Graham EE, Mitchell RF, Reagel PF, Barbour JD, Millar JG, Hanks LM (2010) Treating panel traps with a fluoropolymer dramatically enhances their efficiency in capturing cerambycid beetles. J Econ Entomol 103:641-647

Graham EE, Poland TM, McCullough DG, Millar JG (2012) A comparison of trap type and height for capturing cerambycid beetles (Coleoptera). J Econ Entomol 105:837-846

Handley K, Hough-Goldstein J, Hanks LM, Millar JG, D'Amico V (2015) Diversity and phenology of cerambycid beetles in urban forest fragments of northern Delaware. Ann Entomol Soc Am (in press)

Hanks LM, Millar JG (2013) Field bioassays of cerambycid pheromones reveal widespread parsimony of pheromone structures, synergism by host plant volatiles, and antagonism by components from heterospecifics. Chemoecology 23:21-44

Hanks LM, Millar JG, Moreira JA, Barbour JD, Lacey ES, McElfresh JS, Reuter FR, Ray AM (2007) Using generic pheromone lures to expedite identification of aggregation pheromones for the cerambycid beetles Xylotrechus nauticus, Phymatodes lecontei, and Neoclytus modestus modestus. J Chem Ecol 33:889-907

Hanks LM, Reagel PF, Mitchell RF, Wong JCH, Meier LR, Silliman CA, Graham EE, Striman BL, Robinson KP, Mongold-Diers JA, Millar JG (2014) Seasonal phenology of the cerambycid beetles of eastcentral Illinois. Ann Entomol Soc Am 107:211-226

Imrei Z, Millar JG, Janik G, Toth M (2013) Field screening of known pheromone components of longhorned beetles in the subfamily Cerambycinae (Coleoptera: Cerambycidae) in Hungary. Z Naturforsch C 68:236-242

SAS Institute (2008) Online doc 9.1.3. (http://support.sas.com/onlinedoc/ 913/docMainpage.jsp) 
Katritzky AR, Feng D, Lang H (1997a) Benzotriazole- and 1,2,4-triazolestabilized allylic anions: applications in syntheses of functionalized $\alpha, \beta$-unsaturated ketones, $\gamma$-lactones, $\gamma$-lactams, and $\beta$-substituted esters. J Org Chem 62:706-714

Katritzky AR, Wang Z, Lang H, Feng D (1997b) Novel and facile syntheses of alkenyl, alkynyl, and aryl 1,2-diketones. J Org Chem 62: 4125-4130

Lacey ES, Ginzel MD, Millar JG, Hanks LM (2004) Male-produced aggregation pheromone of the cerambycid beetle Neoclytus acuminatus acuminatus. J Chem Ecol 30:1493-1507

Lacey ES, Millar JG, Moreira JA, Hanks LM (2009) Male-produced aggregation pheromones of the cerambycid beetles Xylotrechus colonus and Sarosesthes fulminans. J Chem Ecol 35:733-740

Lingafelter SW (2007) Illustrated key to the longhorned wood-boring beetles of the eastern United States. Special Publication No. 3, Coleopterists Society, North Potomac

Linsley EG (1962) The Cerambycidae of North America, Part III. Taxonomy and classification of the subfamily Cerambycinae, tribes Opsimini through Megaderini. University of California Publications in Entomology 20, University of California Press, Berkeley

Millar JG, Hanks LM, Moreira JA, Barbour JD, Lacey ES (2009) Pheromone chemistry of cerambycid beetles. In: Nakamuta K, Millar JG (eds) Chemical ecology of wood-boring insects. Forestry and Forest Products Research Institute, Ibaraki, pp 52-79

Mitchell RF, Graham EE, Wong JCH, Reagel PF, Striman BL, Hughes GP, Paschen MA, Ginzel MD, Millar JG, Hanks LM (2011) Fuscumol and fuscumol acetate are general attractants for many species of cerambycid beetles in the subfamily Lamiinae. Entomol Exp Appl 141:71-77

Mitchell RF, Reagel PF, Wong JCH, Meier LR, Dias Silva W, MongoldDiers J, Millar JG, Hanks LM (2015) Cerambycid beetle species with similar pheromones are segregated by phenology and minor pheromone components. J Chem Ecol 41:431-440

Narai Y, Zou Y, Nakamuta K, Mongold-Diers JA, Hanks LM, Millar JG (2015) Candidate aggregation pheromones of two potentially invasive Asian cerambycid species in the genus Xylotrechus. J Econ Entomol (in press)

Ray AM, Swift IP, McElfresh JS, Alten RL, Millar JG (2012a) (R)Desmolactone, a female-produced sex pheromone component of the cerambycid beetle Desmocerus californicus californicus (subfamily Lepturinae). J Chem Ecol 38:157-167

Ray AM, Barbour JD, McElfresh JS, Moreira JA, Swift I, Wright IM, Zunic A, Mitchell RF, Graham EE, Alten RL, Millar JG, Hanks LM (2012b) 2,3-Hexanediols as sex attractants and a female-produced sex pheromone for cerambycid beetles in the prionine genus Tragosoma. J Chem Ecol 38:1151-1158

Rodstein J, McElfresh JS, Barbour JD, Ray AM, Hanks LM, Millar JG (2009) Identification and synthesis of a female-produced sex pheromone for the cerambycid beetle Prionus californicus. J Chem Ecol 35:590-600

Schroeder FC (1996) Identifizierung und Synthese neuer Alkaloide, Hydroxyketone und Bicyclischer Acetale aus Insekten. $\mathrm{PhD}$ thesis, University of Hamburg, Germany

Sikorski W, Reich HJ (2001) The regioselectivity of addition of organolithium reagents to enones and enals: the role of HMPA. J Am Chem Soc 123:6527-6535

Solomon JD (1995) Guide to insect borers of North American broadleaf trees and shrubs. For serv Ag handbook 706. USDA, Washington, DC

Sweeney J, Silk PJ, Gutowski JM, Wu J, Lemay MA, Mayo PD, Magee DI (2010) Effect of chirality, release rate, and host volatiles on response of Tetropium fuscum (F.), Tetropium cinnamopterum Kirby, and Tetropium castaneum (L.) to the aggregation pheromone, fuscumol. J Chem Ecol 36:1309-1321

Wickham JD, Harrison RD, Lu W, Guo Z, Millar JG, Hanks LM, Chen Y (2014) Generic lures attract cerambycid beetles in a tropical montane rain forest in southern China. J Econ Entomol 107:259-267

Zar J (2010) Biostatistical analysis, 5th edn. Pearson Prentice-Hall, Upper Saddle River 